\title{
Novas perspectivas para a psicologia clínica a partir das contribuições de J. P. Sartre ${ }^{1}$
}

\author{
Daniela Ribeiro Schneider \\ Universidade Federal de Santa Catarina
}

\begin{abstract}
RESUMO
O campo da psicologia clínica vem, historicamente, enfrentando dilemas epistemológicos no seu âmago, tais como, a multiplicidade de tendências que a fundamentam, que acarretam na indefinição de seu objeto, além da já questionada herança da perspectiva liberal e do modelo médico, entre outros aspectos, que acabam por questionar sua dimensão prática. Sartre foi um autor que discutiu aspectos fundantes da disciplina psicológica, bem como de seu domínio clínico, propondo concepções inovadoras. Suas obras têm muito a oferecer para o enfrentamento e superação de tais dilemas. O projeto fundamental do trabalho intelectual de Sartre foi reformular tal disciplina, realizando esse propósito no conjunto de suas obras psicológicas, filosóficas, literárias e em seus empreendimentos biográficos. Criador de uma metodologia específica de investigação da realidade humana, explicitada em sua "psicanálise existencial", Sartre fornece as bases para uma psicologia clínica existencialista. Utilizando o recurso de elaborar biografias de escritores conhecidos, Sartre demonstrou ser possível atingir o conhecimento objetivo do ser do sujeito estudado, primeiro passo necessário para uma intervenção científica. A tarefa da psicoterapia sartriana é, pois, colocar o projeto de ser da pessoa em suas próprias mãos, na medida em que isso o viabilizará como sujeito de sua vida e de sua história.
\end{abstract}

Palavras-chave: psicologia clínica; Jean-Paul Sartre; psicologia existencialista.

\begin{abstract}
Clinical psychology from a point of view of J. P. Sartre's contributions

Traditionally, clinical psychology has faced epistemological dilemmas in its core, such as the multiplicity of tendencies that structure it, which leads to an undefinition of its object. Among other aspects, the legacy it received from the liberal perspective and the medical model are also problematic and they have already been put in question. This affects its practical dimensions. Sartre was an author who discussed aspects of the basis upon which psychology was built, as well as clinical facets and proposed some innovative concepts. His work has much to offer to overcome such dilemmas. The fundamental project in Sartre's intellectual work was reformulating psychology in his set of psychological, philosophical, literary works and in his biographical enterprises. Sartre was the creator of a new psychological theory as of a specific methodology to investigate the human reality. Both of them were explained in his "existential psychoanalysis" where Sartre gives the basis for an existential clinical psychology. The duty of the sartrean psychotherapy is to put the being project of the individual into his own hands, turning him into the manager of his own life and his own history.
\end{abstract}

Keywords: clinical psychology; Jean-Paul Sartre; Existential Psychology.

\section{I - 0 campo da psicologia clínica}

No imaginário popular a clínica é a área predominante e identitária da psicologia. Esse imaginário encontra seu suporte no fato do psicólogo clínico ser, efetivamente, o modelo hegemônico de profissional da psicologia, conforme atestam uma dezena de pesquisas realizadas a partir do início década de 1980, no Brasil, entre elas as do Conselho Federal de Psicolo- gia $(1988 ; 1992 ; 1994)$. No início da década de 90 surgiram, na profissão, várias áreas emergentes (psicologia hospitalar, jurídica, dos esportes, saúde pública etc.), geradas em função das demandas do mercado de trabalho, de mudanças nas relações sociais, bem como nas concepções teóricas, o que levou a uma certa modificação na já consolidada concentração dos psicólogos na área clínica. Portanto, a clínica é a área 
mais conhecida e, como conseqüência, a mais estereotipada no campo da psicologia.

Há muita discussão sobre as razões desse predomínio. Entre elas, não podemos deixar de considerar, a grande influência da psiquiatria e, portanto, do modelo médico, na constituição dessa disciplina, o que ajudou a definir os contornos da prática clínica e a consolidar o prestígio herdado do poder médico. Além disso, a tarefa de realizar a adaptação dos indivíduos desajustados, função para a qual a clínica psicológica foi inicialmente concebida, conforme atesta vários de seus historiadores (Mensh, 1971), serviu à necessidade premente da sociedade de manter seu status quo.

Essas reflexões iniciais nos levam a indagar acerca das dificuldades e impasses em torno da delimitação da função clínica em psicologia. A partir da década de 80 , frente a todas essas indefinições, além da constatação de sua dimensão ideológica, bem como de seu predomínio hegemônico, muitos psicólogos e pesquisadores brasileiros começaram a questionar aspectos basilares da área clínica (Conselho Federal de Psicologia, 1988; 1992; 1994; Campos, 1992):

a) o fato de a psicologia clínica seguir e propalar um modelo de profissão liberal, pautada pela démarche médica, voltada para o atendimento de uma camada privilegiada da população crítica de ordem político-ideológica;

b) a sua concepção de homem ser individualista, ahistórica e associal, advinda de uma herança da psiquiatria clínica, de perspectiva mais organicista e de uma psicologia subjetivista, sustentada em uma filosofia idealista e mentalista, além de sua relação com a concepção liberal de sociedade - crítica de cunho mais teórico e epistemológico, bem como ideológico;

c) a concepção de saúde mental que a sustenta ser pensada em termos de normal/anormal, herança do modelo empírico, classificatório, que trabalha na direção de enquadramento dos comportamentos desviantes - crítica de cunho epistemológico e ideológico;

d) a sua função de ajustamento dos indivíduos com comportamento desadaptado à sociedade, cumprindo um papel social de "manutenção do status quo", herança da medicina higienista do século XVIII e da psiquiatria clássica - crítica de cunho ideológico e político;

Essas críticas, fundamentais para se pensar o fazer do psicólogo, acabaram por se tornar um questionamento de todo o modelo clínico e de sua prática mais conhecida, a psicoterapia. Esses questionamentos adquiriram, de forma geral, uma ênfase mais políticoideológica, cuja solução deveria passar pela conscientização da função social do psicólogo, através de uma luta política na interioridade da categoria, na formação do psicólogo e na sociedade. Importantes conquistas foram feitas nesse campo. No entanto, no rumo desses questionamentos, muitas vezes se deixou de lado o aspecto teórico e epistemológico das críticas, fundamentais por apontarem lacunas centrais na constituição da ciência psicológica, posicionando-se, muitas vezes, aprioristicamente, pela negação da clínica ou da psicoterapia e não pela superação dos impasses dessa importante área de atuação do psicólogo.

Dessa forma, o presente artigo visa trazer novas contribuições para o campo da psicologia clínica, que enfrentem seus problemas de (in)definição, seus dilemas teóricos e epistemológicos. Nessa direção, a psicologia consolidada por Jean-Paul Sartre, que se instaura em um horizonte epistemológico, teórico e ideológico diferente do da psicologia empírica, da psiquiatria e da psicanálise freudiana, por assumir uma perspectiva histórica, dialética, não mentalista e não subjetivista, tem muito a oferecer para a superação dos impasses enfrentados pela psicologia clínica.

\section{II - Jean-Paul Sartre - um intelectual de sua época}

O grande desafio de Jean-Paul Sartre (1905-1980) foi responder a alguns problemas que estavam propostos aos cientistas, filósofos e pensadores de sua época (Bertolino,1995): os dilemas trazidos pelo idealismo e racionalismo, por um lado, e pelo materialismo e positivismo, por outro, concretizados em questões como a problemática do conhecimento, a discussão acerca da objetividade nas ciências; a necessidade de revisão da filosofia, trazida pelo marxismo, que postulava um conhecimento que remetesse à realidade sócio-histórica, pois "bastava de contemplar o mundo, cabia, agora, transformá-lo!" (Marx \& Engels, 1987). O contexto cultural estava a exigir, pois, a produção de um conhecimento que partisse e voltasse ao homem concreto. Era o que reclamava Politzer $(1965 ; 1998)$ com a perspectiva de uma psicologia concreta, era o que perseguia Vygotski (1996) na discussão e crítica ao método da psicologia, lá pelos anos 1920 e 1930. Era também o que postulava a fenomenologia, no final do século XIX e início do século XX, pautandose em seu princípio da volta às coisas mesmas. Sartre inseriu-se no âmago mesmo das indagações presentes no contexto da evolução do pensamento daquele mo- 
mento, problematizando suas questões elementares e propondo soluções que visavam superar impasses gerados, tanto no campo filosófico e epistemológico, quanto no psicológico. Decorre daí sua importância como um dos intelectuais mais relevantes do século XX.

Em função desse contexto, Sartre foi desenvolvendo seu interesse pela disciplina psicológica. Desde o início de seu trabalho intelectual pretendeu criar uma psicologia que se opusesse àquelas compreensões do humano que lhe pareciam, de um lado, abstratas e despregadas da realidade e, de outro, mecanicistas e causalistas. Descreve Simone:

O que interessava antes de tudo eram as pessoas. $\grave{A}$ psicologia analítica e empoeirada que ensinavam na Sorbonne, ele desejava opor uma compreensão concreta, logo sintética, dos indivíduos. Essa noção ele tinha encontrado em Jaspers, cujo tratado de psicopatologia, escrito em 1913, fora traduzido em 1927; sendo que corrigira as provas do texto francês com Nizan. (Beauvoir, 1960, p. 52)

Beauvoir descreve aqui como foi sendo gestado o interesse do filósofo pela fenomenologia, a qual possibilitou que, pouco a pouco, ele adentrasse no questionamento e elaboração acerca da disciplina psicológica, pois era ela o meio de fazê-lo aproximar-se de seu objetivo maior: teorizar sobre o homem concreto, com seus "suores e suas dores" e seu campo de possibilidades de ser (Sartre, 1960).

Os biógrafos de Sartre fazem questão de salientar a importância da psicologia em seu projeto intelectual.

A filosofia seria, de qualquer maneira, uma propedêutica para a psicologia e para sua criação romanesca. Nas revisões da prova de 'Psicopatologia Geral' de Jaspers, nas visitas às apresentações de casos dos doentes do Hospital Sainte-Anne, onde ele passava seus domingos de manhã, em companhia de Nizan, Aron e Lagache, em seu diploma de estudos superiores, quando sustentou, com orientação de Henri Delacroix, sua tese sobre 'A imagem na vida psicológica: papel e natureza', Sartre decifrava, sobretudo, o campo da psicologia. (Cohen-Solal, 1986, p. 140)

Dessa forma, os especialistas na obra sartriana deixam claro a proposição do filósofo em questionar esse campo disciplinar e propor uma nova psicologia, de base fenomenológica.

Sendo assim, o existencialista começou suas incursões teóricas formulando proposições no campo da psicologia, conforme podemos verificar em seus primeiros escritos: A Imaginação (Sartre, 1936), A Transcendência do Ego (Sartre, 1937), Esboço de uma Teoria das Emoções (Sartre, 1939), O Imaginário (Sartre, 1940). Voltou-se, porém, à filosofia pela necessidade técnica de melhor fundamentar seus estudos da psicologia (Bertolino, 1995). O conjunto de sua obra filosófica e psicológica será descrita com maiores detalhes logo adiante, possibilitando compreender sua trajetória teórica.

Esse intelectual, mais conhecido pelo seu perfil de filósofo, foi, portanto, um pesquisador sistemático da psicologia, sendo que sua obra técnica inscreve-se, boa parte dela, nesse campo. No entanto, essa perspectiva é pouco conhecida ou discutida, ou ainda, sua obra é traduzida como tendo, principalmente, um cunho filosófico, o que é verdadeiro, mas não é sua total abrangência. Poder-se-ia quase afirmar que a filosofia sartriana foi o meio, o fio condutor de boa parte de suas elaborações psicológicas, como podemos verificar na citação de Cohen-Solal logo acima. Entre os próprios psicólogos, a psicologia de Sartre, em seu conjunto, é desconhecida e pouco valorizada; estudam nele certas temáticas, como a noção de projeto, de liberdade, etc, entendidas mais como contribuições filosóficas de Sartre à área. Poucos, porém, compreendem sua relevância na problematização da disciplina psicológica. Essa relevância encontra-se na exposição de uma psicologia em moldes totalmente diversos dos até então existentes, ao propor a superação de uma série de dificuldades e impasses presentes no âmago das formulações da psicologia empírica e da psicanálise freudiana, conforme detalharemos oportunamente nestas reflexões.

Sendo assim, o projeto fundamental do trabalho técnico de Sartre foi reformular a psicologia, conforme já foi demonstrado pelas dissertações de Bertolino (1979) e Moutinho (1995), tese que procuraremos defender e discutir aqui nesse artigo.

\section{III - Os caminhos teóricos de Sartre}

Seu interesse pela elucidação da situação do homem em sua realidade concreta, que advinha de sua crítica à filosofia e psicologia idealista, coloca Sartre nos trilhos da fenomenologia. Seu primeiro contato com essa filosofia ocorreu com a tradução do tratado de psicopatologia fenomenológica de Jaspers, na qual encontrou, entre outras, a noção de compreensão, em oposição à de explicação causal, típica do positivismo, que tanto criticava; depois, veio a descoberta dos auto- 
res que serão seus principais interlocutores - Husserl e Heidegger. O filósofo solicitou uma bolsa para estudar fenomenologia em Berlim, passando lá o ano de 1933, quando teve oportunidade de pesquisar essa filosofia em suas fontes originais.

O primeiro texto que Sartre produziu, esboçando suas reflexões críticas sobre as contribuições filosóficas da fenomenologia, escrito em 1934 e publicado somente em 1939, é o conhecido Uma idéia fundamental da fenomenologia de Husserl: A intencionalidade (Sartre, 1968), no qual explora a idéia-chave que guiará sua filosofia e psicologia, a intencionalidade, que postula que toda "consciência é sempre consciência de alguma coisa", ou seja, a consciência é sempre relação a uma exterioridade. Essa noção é o fundamento para questionar o "mito da interioridade" ou, como ele designa nesse texto, a velha "filosofia alimentar", recolocando essa disciplina em novas bases. A fenomenologia lhe fornece "os meios de pôr fim à idéia de representação e constituir assim uma nova psicologia, o que ele procurará fazer nos anos subseqüentes - uma psicologia da imagem, da emoção, mesmo mais tarde uma psicanálise existencial" (Moutinho, 1995, p. 163).

Aos poucos, Sartre irá construindo sua crítica a Husserl, principalmente ao idealismo pressuposto em toda a sua proposta fenomenológica, até o momento em que precipitará sua ruptura com as idéias do referido filósofo. Sartre, a partir de 1939, passa a centrar seus estudos principalmente na obra de Heidegger. Vai incorporando, um após outro, conceitos como "ser-no-mundo", "mundaneidade", "nada", "temporalidade", mas sempre de forma crítica. De qualquer maneira, a fenomenologia que Sartre foi aprender na Alemanha será decisiva na constituição de sua obra (Coorebyter, 2000).

A tese de conclusão de sua pós-graduação em Berlim foi seu primeiro escrito sobre a psicologia fenomenológica, sob a denominação de A Transcendência do Ego (1937/ 1994²). Nele descreve a ontologia do eu e os processos de constituição da personalidade, quando defende que um dos grandes impasses presentes na filosofia e na psicologia, até então vigentes, é o fato de não diferenciarem a consciência do ego. Sartre estabelecerá uma distinção essencial entre essas duas dimensões do homem, demonstrando que o ego, ao contrário do que se afirmava, não é imanente à consciência, ou seja, não é seu habitante, mas sim, transcendente, objeto do mundo. Pretendia superar, com isso, o solipsismo (a concepção de um sujeito sustentado em si mesmo, o mundo sendo desdobra- mento da perspectiva pessoal de cada um), bem com a chamada ilusão substancialista (a consciência considerada como uma substância em si), conceitos sempre presentes nas filosofias idealistas.

A partir de então o caminho torna-se irreversível. As posições defendidas em A Transcendência do Ego se aprofundarão no restante de seus estudos. Suas obras, destacadamente as de cunho filosófico e psicológico, constituem-se em um conjunto articulado de concepções ontológicas, antropológicas, psicológicas e metodológicas.

Somente em 1938 será publicado seu romance $A$ Náusea (1938/2000), que já vinha redigindo desde 1933-4. Romance centrado na noção de contingência, ou seja, do confronto do sujeito com a gratuidade da existência, narra a história de Roquentin, que sofre de uma "metamorfose insinuante e horrível de todas as sensações" (Sartre, 2000), passando por um verdadeiro processo terapêutico, no sentido da alteração do seu modo de se lançar no mundo e da redefinição de seu projeto de ser, na medida em que havia tido impasses psicológicos justamente por experimentar esse projeto inviabilizado. Sartre, nessa obra, insere uma série de reflexões filosóficas, ainda que em linguagem literária. Um dos fatos que o levou a escrever A Transcendência do Ego, foi a tentativa de elucidação técnica de sua expressão literária em A Náusea (Contat \& Rybalka,1970) .

Em 1936, ainda sob forte influência da fenomenologia de Husserl, dedica-se a estudar as questões ligadas à imagem mental, escrevendo uma obra cuja introdução tem o título de A Imaginação (1936/1987), onde faz uma revisão das principais teorias existentes sobre a psicologia da imaginação. Poucos anos mais tarde é publicado o restante dessas reflexões, sob o título de $O$ Imaginário: psicologia fenomenológica da imaginação (1940/1996), onde Sartre descreve sua própria compreensão dos fenômenos do imaginário. Partindo da noção de intencionalidade, concebe a imaginação como uma das formas da consciência se relacionar com o mundo, nesse caso com um objeto ausente ou inexistente. Portanto, a consciência imaginante não é algo que se dá "dentro" do sujeito, mas na sua relação com o mundo. $\mathrm{O}$ imaginário permite ao sujeito transcender a situação dada em direção ao que ainda não é, ao futuro. Possibilita, também, a retomada daquilo que já foi, o passado. Dessa forma, o imaginário é fundamental na definição do ser do homem, já que o coloca frente ao seu projeto de ser e a sua história.

Interação em Psicologia, Curitiba, jan./jun. 2006, (10)1, p. 101-112 
Vemos aqui os caminhos teóricos trilhados por Sartre que desembocam, nos anos de 1937/8, no seu tratado sobre La Psyché, cuja pretensão era elucidar a realidade humana a partir da existência concreta do sujeito, elaborando uma nova psicologia. No entanto, segundo Bertolino (1995) "teve de se rever a meio caminho, devido aos obstáculos de ordem técnica". Seria necessário resolver, primeiramente, questões de ordem ontológica (teoria do ser da realidade) e antropológica (teoria do ser do homem), para depois resolver as questões do psicológico. Sartre nos explica, em seu Esboço de uma Teoria das Emoções (1939/1975), que foi o fragmento publicado das 400 páginas que já havia escrito do referido tratado:

Por outro lado, a psicologia, encarada como ciência de certos fatos humanos, não poderia ser um começo, porque os fatos psíquicos com que nos deparamos nunca são os primeiros. São sim, na sua estrutura essencial, reações do homem contra o mundo; pressupõe, portanto, o homem e o mundo e não podem assumir o seu verdadeiro sentido se, primeiramente, essas duas noções não forem elucidadas. Se desejarmos fundar uma psicologia, teremos de ir bem mais alto do que o psíquico, mais alto do que a situação do homem no mundo; teremos de ir até à origem do homem, do mundo e do psíquico. (Sartre, 1939, p. 18)

Portanto, Sartre defronta-se com uma questão técnica fundamental. Constata que não conseguiria fundar uma psicologia, como era sua pretensão, explicitada claramente na citação acima, se não revisse as bases filosóficas dessa ciência, se não lhe constituísse outra ontologia, que viabilizasse a compreensão da realidade, do homem, em uma outra perspectiva, já que a filosofia que tinha a seu dispor no contexto de sua época não lhe fornecia os subsídios necessários para tal empreendimento.

Passa a escrever, então, seu conhecido $\mathrm{O}$ Ser e o $\mathrm{Na}$ da: ensaio de ontologia fenomenológica (1943/1997), no qual realiza a necessária revisão da filosofia, concretizando-se na proposição de uma nova ontologia fenomenológica. Nesse livro dialoga com autores como Husserl e Heidegger, apoiando-se em muitas de suas noções, ao mesmo tempo em que os critica profundamente.

Nesse ensaio de ontologia, Sartre aprofunda a noção de consciência adquirida em Husserl, concebida pelo existencialista como a dimensão transfenomênica do sujeito, o absoluto de subjetividade; absoluto tomado pelo existencialista no sentido filosófico, do ser que é ilimitado, incondicional, incontestável. Portanto, Sartre considera a subjetividade, aqui compreendida pela noção de consciência, enquanto uma dimensão indescartável da realidade, daí ser um absoluto em termos ontológicos. No entanto, esse absoluto de subjetividade é não substancial, ou seja, não se sustenta em si mesmo, na medida em que a "consciência é sempre consciência de alguma coisa" (princípio da intencionalidade), necessitando, assim, das coisas para ser. Constitui, portanto, a região ontológica que Sartre designa de para-si, na medida em que é pura relação, puro movimento para a exterioridade, não se sustentando em-si mesma. A consciência é o que ela não-é, na medida em que seu ser é ser relação a algo. Ela é assim, o nada, o não-ser que se acrescenta ao ser. Eis que o outro absoluto, o de objetividade, é, então, também indescartável para a constituição da realidade. A objetividade, compreendida pelas coisas, não depende da consciência para existir, posto que os objetos, a natureza, os corpos, a materialidade existem em-si, independente do que se percebe, pensa, imagina ou constata sobre eles. Porém, o ser que é em-si não tem alteridade, na medida em que não estabelece relação por si mesmo, necessitando da consciência para ser organizado, sistematizado, nomeado, significado. Portanto, as duas regiões ontológicas que compõem a realidade: o ser e o nada, as coisas e a consciência, ou ainda, o em-si e o para-si, são dois absolutos, porém relativos um ao outro. Relativos porque, o primeiro (em-si) existe independente do segundo (consciência), mas só se organiza, só ganha sentido, pela presença deste. O segundo (para-si) para existir depende da relação estabelecida com aquele (com as coisas), apesar de ser distinto dele.

Sartre define, portanto, sua ontologia a partir da dialética entre o ser e o nada ou entre a objetividade e da subjetividade, superando as ontologias idealistas ou espiritualistas (nas quais as coisas ou a objetividade são absorvidas pelo sujeito, consciência, idéia ou espírito) e as ontologias materialistas (nas quais o sujeito ou a subjetividade são absorvidos pela matéria, objeto ou ambiente).

Como decorrência dos caminhos que vinha trilhando anteriormente, seu livro de ontologia $O$ Ser e o Nada é perpassado por discussões de ordem psicológica. Vários temas fundamentais como o homem enquanto ser-no-mundo, a temporalidade psíquica, as relações com o corpo, o projeto de ser, a liberdade humana, etc, são ali desenvolvidos. No capítulo intitulado Psicanálise Existencial, descreve uma proposta metodológica para a psicologia, de forma a elucidar, 
"de forma rigorosamente objetiva, a escolha subjetiva pela qual cada pessoa se faz pessoa" (Sartre, 1943, p. 662).

Em função de sua intenção de construir uma nova psicologia, não só em termos teóricos, mas também metodológicos viabilizando um instrumental teóricoprático que possibilitasse a compreensão objetiva da vida de um homem, como podemos verificar no capítulo "psicanálise existencial", Sartre parte para a realização de empreendimentos biográficos. Dedicar-se-á a escrever biografias de escritores conhecidos e, através da análise de suas obras e dos dados de suas histórias, elabora a compreensão antropológica e psicológica dos personagens escolhidos. Seus livros Baudelaire (1947) e Saint Genet:Autor e mártir (1952/2002) são seus primeiros ensaios para viabilizar sua psicologia concreta. Compreender o destino eleito por esses dois escritores, a partir do embate com as contingências que os cercavam e de como essa escolha fundamental se expressava em suas obras, foi um dos seus objetivos centrais.

A influência fundamental em seu pensamento de autores como Hegel e Marx, aliada ao enfrentamento das questões sociais e culturais por Sartre nos anos 40 e 50, bem como a necessidade interna de aprofundar aspectos de sua teoria que ainda estavam por ser melhor elucidados, levaram-no a se debruçar sobre temáticas como a práxis individual e coletiva, a história, a dialética, os grupos organizados, as instituições. Tais reflexões resultaram na elaboração de um dos seus livros mais conhecidos, a Crítica da Razão Dialética (1960/2002a). Na introdução a essa grande obra, chamada de Questão de Método, o existencialista volta a aprofundar as possibilidades metodológicas do conhecimento concreto da realidade humana. Debate com o marxismo, apontando que este deve rever suas bases antropológicas, sob pena de perder o homem, desumanizar-se, ao reduzir-se a análises progressivas, gerais, que implicam um descaso com o singular e a subjetividade, aspecto central da realidade social.

No início dos anos 1970, Sartre realiza, por fim, o trabalho que já vinha planejando desde a época em que escrevera sua proposta de uma psicanálise existencial, a monumental biografia sobre Flaubert, com mais de três mil páginas, intitulada de $O$ Idiota da Família: Gustave Flaubert, de 1821 a 1857 (1971)², em que realiza uma síntese de todas as reflexões teórico-metodológicas que elaborou no conjunto de sua obra. Nela busca unificar as contribuições da psicanálise, no sentido da busca de esclarecimento do ser de um sujeito individual, reportando-se à sua história, à sua infância, com as da análise marxista, no sentido de uma lógica dialética empregada na compreensão do contexto antropológico e sociológico da constituição desse escritor.

Tem-se aí o caminho teórico percorrido por esse pensador. Como podemos verificar pelo conjunto de sua obra técnica, Sartre construiu uma teoria e uma metodologia que colocam a psicologia sobre novas bases. Tal realização se deveu à rigorosidade dos seus estudos e à sua perspicácia em compreender que as mudanças deveriam começar por rever os fundamentos ontológicos e antropológicos dessa ciência.

\section{IV - Síntese das principais asserções da filosofia e psicologia sartriana ${ }^{4}$}

Ao acompanhar a evolução do pensamento sartriano, pode-se constatar que esse estudioso propôs uma nova ontologia, que questiona os fundamentos metafísicos do pensamento ocidental e fornece as bases para o direito à cidadania da ciência (Bertolino, 1995), nos seguintes termos: 1) ao estabelecer que a realidade se estrutura em termos de duas regiões ontológicas - o ser e o nada, ou as coisas e a consciência, ou o em-si e o para-si - compreendidas como dois absolutos relativos, quer dizer, como dois aspectos distintos e inelutáveis da realidade, porém relativos um ao outro. Em outras palavras, a realidade é resultante da relação dialética entre a subjetividade e a objetividade, como vimos acima; 2) ao distinguir consciência (aspecto indescartável da realidade humana, estrutura essencial de sua ontologia, que possibilita ao homem estabelecer relações) de conhecimento (não mais um saber $a$ priori, mas um aspecto segundo, resultante da produção do homem), rompendo com a primazia do conhecimento típicas do idealismo e racionalismo, viabilizando, assim, o homem enquanto sujeito do conhecimento.

Essa ontologia fenomenológica foi o eixo norteador das profundas alterações que propôs à antropologia que, segundo ele, deve ser estrutural e histórica, pretendendo, com isso, "resgatar o sujeito concreto no seio do marxismo" (Sartre, 1960), fundamentando a compreensão de que o homem é aquele que faz e é feito pela história. A antropologia deve ser a síntese dialética da relação entre indivíduo e sociedade, sujeito e materialidade.

As concepções da fenomenologia de Husserl e Heidegger, do existencialismo de Kierkegaard e da dialética de Hegel e Marx, que o influenciaram so- 
bremaneira, retrabalhadas e superadas por sua própria ontologia e antropologia, forneceram o substrato necessário para Sartre construir uma nova psicologia, que estabelece, definitivamente, um corte epistemológico, metodológico e teórico com a psicologia empírica e seus impasses, bem como com a psicanálise freudiana e sua lógica pautada no determinismo psíquico ${ }^{5}$.

Nesse horizonte, Sartre elaborou:

1) uma nova ontologia do eu, ao concluir que o ego (dimensão do sujeito) não é um habitante da consciência (dimensão da subjetividade), como sustentam muitas psicologias empíricas e a psicanálise, que caem na ilusão substancialista, mas sim um ser do mundo, objetivo, transcendente; o que permite que a personalidade possa ser inteiramente conhecida;

2) uma nova teoria do imaginário, consciência irredutível e autônoma, considerada por ele uma das formas essenciais do homem se relacionar com a realidade, na medida em que o permite transcender a situação dada em direção ao novo, ao diferente, ao futuro;

3) uma nova teoria das emoções, compreendidas como a experimentação psicofísica da pessoa frente a situações significativas, que expressam suas afetações e escolhas de ser;

4) uma nova teoria dos processos de socialização e constituição dos grupos, fundamentada na dialética da realidade humana, destacando o papel essencial do indivíduo na organização social, bem como o dos grupos e da cultura para a estruturação psicossocial dos sujeitos. Em Sartre, o sujeito concreto tem um papel fundamental, mas sempre mediado pelo contexto efetivo onde está inserido (época histórica, classe social, estrutura familiar). Fundamenta, assim o método progressivo regressivo, que pressupõe que a investigação da realidade leve em conta as situações singulares inscritas no contexto universal e, ao mesmo tempo, considera as situações universais em seu impacto nas individualidades e grupos.

Construiu, enfim, nesse conjunto de teorias, uma nova proposta de inteligibilidade da dimensão psicológica do indivíduo, fundamentando concepções importantes, tais como: o homem como um ser-nomundo; o homem enquanto um ser temporal, histórico; a dialética da relação eu/outro, indivíduo/sociedade, subjetividade/objetividade; o homem como projeto e desejo de ser, como alienação e liberdade - enfim, aspectos que desembocam em sua acepção da personalidade como resultante de um processo de construção, onde a "existência precede a essência", o que coloca o homem como sujeito de seu ser.

Esses pressupostos forneceram para Sartre a possibilidade de delinear importantes contribuições para o campo da psicopatologia. Sustentado em Jaspers (1979) e servindo de subsídio aos antipsiquiatras, o existencialista vai compreender a psicopatologia a partir do núcleo da vida e da história concreta do sujeito. Ela é uma perturbação, sempre psicofísica, que acontece em função do movimento do sujeito no mundo, resultante de sua história de relações. Dessa forma, ao contrário da psicopatologia psiquiátrica que pretendem entender o homem a partir da doença, dando uma ênfase às determinações genéticas, Sartre compreende a doença a partir do homem, o patológico a partir de seu existir concreto no mundo. A elaboração de biografias de escritores conhecidos foi o recurso utilizado pelo existencialista para demonstrar concretamente a viabilidade teórico-prática de suas concepções. Essas são, portanto, as bases para que se possa viabilizar uma psicologia clínica em perspectiva sartriana.

\section{V - Sartre e o caminho metodológico em direção a uma psicologia clínica científica}

Sartre explicita claramente seu método para a investigação da realidade psíquica, no capítulo de $O$ Ser e o Nada intitulado "Psicanálise Existencial", complementando-o em seu Questão de Método, descrevendo-o nos termos que explicitaremos abaixo.

O objetivo da psicanálise sartriana é decifrar o nexo existente entre os diversos comportamentos, gestos, emoções, estados, ações, pensamentos do sujeito concreto, ao extrair o significado de cada um destes aspectos em direção a um fim. Isto quer dizer que a psicanálise existencial deve decifrar o projeto de ser de cada indivíduo estudado, pois é ele que define o que são e para onde se encaminham os diferentes movimentos de uma pessoa no mundo.

O ponto de partida da investigação deve ser os aspectos concretos da vida de um sujeito, ou seja, os fenômenos de sua vida de relações, de homem em situação. Aqui se delineia o método sartriano: por um lado, ele é comparativo, ou seja, estabelece ligações entre os diversos aspectos que presidem a vida de um sujeito, procurando atingir o projeto original que dá sentido ao conjunto; é, nesse sentido, um método compreensivo ou sintético, já que pretende chegar "à 
intuição do psíquico, atingida por dentro", como diria Jaspers (1979). Por outro, ele deve ser progressivo e regressivo, como Sartre (1960) trabalha no Questão de Método, ou seja, deve situar os aspectos antropológicos (época, cultura, nível social, etc.), que definem os contornos de ser de um sujeito concreto, reenviandoos ao mesmo tempo, à sua rede sociológica, bem como à sua subjetividade, a fim de se compreender a apropriação peculiar desses aspectos mais universais. A expressão da pessoa em gestos, atos, palavras, obras, devem ter, assim, sua dimensão subjetiva e objetiva. O sujeito é um singular/universal, pois ao mesmo tempo em que é idiossincrático, ele é resultante de seu tempo, de sua cultura e, portanto, uma ponte para compreendê-los.

A concepção de homem que subjaz na teoria sartriana é histórica e dialética, segundo a qual o sujeito só pode ser compreendido levando-se em conta sua história individual, tanto quanto a de sua conjuntura familiar e a de seu contexto social e cultural, tendo como fundo de sustentação a noção que ele se faz e é feito no/por esse conjunto de fatores. Toda a psicologia existencialista construída por Sartre pauta-se nessa antropologia, servindo de embasamento teórico para a concretização de sua psicanálise existencial.

Sartre, com a clareza do potencial clínico de sua psicanálise, afirma que sua "psicanálise ainda não encontrou o seu Freud" (Sartre, 1943, p. 663), assinalando que o que faltava a ela era ser posta em prática.

A estratégia por ele utilizada, a partir de seus delineamentos teórico-metodológicos, em vistas à viabilização de sua psicanálise existencial, foi o da elaboração de biografias, buscando uma compreensão rigorosa do ser dos seus biografados, ao esclarecer o processo de suas personalizações, em suas dimensões objetivas e subjetivas, chegando ao projeto e ao desejo de ser, que são o combustível dos fenômenos psicológicos e da história de vida de cada sujeito, como fez com Genet e Flaubert. Essas biografias trazem, com isso, uma grande contribuição ao entendimento dos caminhos de uma psicologia clínica sartriana.

Para Sartre (1939) a tarefa da ciência, é esclarecer as condições de possibilidade de certos fenômenos de ordem geral, ou seja, é investigar os fatores que são os determinantes para a ocorrência de um dado fenômeno estudado. Primeiramente deve-se, no entanto, investigar as variáveis que o delimitam e que interferem para que ele se desenvolva da forma como deva ser. Depois disso é que se deve investigar suas determinantes.
A tarefa da ciência psicológica deve ser, portanto, investigar as condições de possibilidades de certos fenômenos de ordem psicológica ocorrerem, considerando-os em suas essências específicas, suas variáveis constitutivas, seus significados (Sartre, 1939). Sendo assim, a psicologia clínica, cujo objeto é a personalidade e a psicopatologia do paciente, para ser científica, em sua teoria, em seu método e em seus procedimentos, deve investigar quais as condições de possibilidade para um sujeito chegar a ser quem ele é, ou seja, como chegou a constituir-se determinada personalidade, sustentada em um projeto de ser específico, esclarecendo como foi que se complicou psicologicamente. Deverá, assim, poder especificar, em sua história, os contextos antropológicos (cultural, material) e sociológicos (rede de relações e de mediações de ser) que forneceram as condições de sua personalização e psicopatologização.

No entanto, no processo científico deve-se sempre começar pelo momento atual do fenômeno para depois esclarecê-los em sua gênese. O primeiro momento metodológico necessário é, assim, a demarcação do fenômeno, quer dizer, no caso da clínica, a definição clara da sintomatologia e do quadro psicopatológico do paciente, ou seja, a elaboração do psicodiagnóstico. Ele é que definirá os rumos da intervenção.

O segundo momento é o da elaboração da problemática ou do equacionamento do teorema em torno das complicações do paciente. Realiza-se essa elaboração investigando as variáveis fundamentais na constituição dos impasses psicológicos do paciente, compreendidos no horizonte da personalidade do paciente, ou seja, a partir de sua dinâmica psicológica, da forma como ele se sabe sendo tal sujeito específico, em seu sistema de certezas de ser (Bertolino, 2004; Sartre, 1952). Aqui é fundamental a inteligibilidade de Sartre acerca da personalidade, considerada sempre como um fenômeno resultante da dialética entre objetividade e subjetividade. Portanto, as condições de possibilidade de alguém se constituir sujeito estão dadas em suas relações concretas, inseridas em uma situação mais próxima, de sua rede de mediações, aqui definidas como contexto sociológico e, em uma mais abrangente, dadas pela cultura a que pertence, sua classe social, sua condição material, os sistemas de racionalidades que o influenciam, aqui definido como contexto antropológico (Bertolino, 2004; Sartre, 1952). Essas circunstâncias são apropriadas ativamente pelo sujeito concreto, ainda que de forma alienada, levando-o a experimentar-se psicofisicamente 
determinado a ser esta ou aquela pessoa. Portanto, o esclarecimento desses contextos é fundamental na compreensão da problemática do paciente.

Eis o horizonte metodológico de uma psicologia clínica que pretenda seguir as acepções sartrianas.

\section{VI - A psicologia clínica em Sartre}

$\mathrm{O}$ existencialista demonstra em suas biografias como trabalhar com o fenômeno psicológico em seus diferentes componentes e níveis - sociais, culturais, psicológicos - dos quais emerge o sujeito concreto, em carne e osso, com o seu desejo de ser, com os conflitos que lhe são decorrentes, às voltas com sua eleição original. Realiza, portanto, o que poderíamos chamar metaforicamente de uma radiografia psicológica do sujeito, na medida em que deixa translúcidas as raízes de sua problemática psicológica, a localização das contradições de seu ser, definidas a partir do resgate de seu projeto de ser, originado de seu movimento no conjunto de suas relações, ou seja, de seu movimento no mundo.

Essa pormenorizada compreensão psicológica permite, no caso de um paciente de psicoterapia, que seja realizado um planejamento do processo psicoterapêutico, possibilitando definir quais são os aspectos essenciais a serem trabalhados em uma intervenção clínica: as principais variáveis que constituíram seus impasses psicológicos, as relações fundamentais de serem trabalhadas, a ordem das intervenções, os procedimentos necessários a serem adotados. Com isso, possibilita uma intervenção com vistas a superar os impasses de ser do paciente, a mudar sua personalidade, se assim se fizesse necessário.

Portanto, a partir da metodologia compreensiva estabelecida nas biografias, Sartre fornece condições para um delineamento daquilo que seria a primeira etapa fundamental de um processo psicoterapêutico científico: a da elaboração da compreensão psicoterapêutica, sem a qual o rigor do processo torna-se questionável, já que é ela que permite que o terapeuta obtenha clareza e segurança de como e onde intervir para alterar o fenômeno, ou ainda, obtenha clareza de onde intervir para fornecer ao paciente condições de redimensionar sua vida e seu projeto de ser, ao tomar a sua história e o seu ser em suas mãos, já que esse é o principal objetivo de cura em um processo psicoterapêutico na perspectiva sartriana: possibilitar as mudanças que se fazem necessárias, para que o paciente possa assumir a responsabilidade de seu ser e se tornar sujeito de sua história.
E qual é a tarefa da psicoterapia? Justamente a de colocar o ser da pessoa em suas próprias mãos, na medida em que isso a viabilizará como sujeito. Qualquer processo psicoterapêutico só vai encontrar solução se possibilitar ao paciente converter-se em sujeito de sua própria história, de seu ser, para, assim, adquirir condições de se tornar um sujeito social íntegro, ciente de também ser sujeito da história social, de ser um cidadão. Esse deve ser o caminho da clínica: viabilizar o homem enquanto sujeito.

A cura em uma psicologia clínica de perspectiva sartriana só é possível pela condição de o paciente superar a situação em que está submetido e poder fazer alguma coisa daquilo que os outros fizeram dele. Curar é transcender os problemas e colocar a resolução da questão ontológica do paciente dentro de novos parâmetros, em que seu projeto e desejo de ser sejam viabilizados. A cura, em uma perspectiva sartriana, nunca poderia ser, portanto, uma conformação ao que o paciente é, um assumir a sua condição, uma aceitação de si mesmo, um auto-conhecimento, uma adaptação às circunstâncias sociais, como pregam muitas outras psicoterapias. Não! A psicoterapia existencialista sartriana só faz sentido se possibilitar ao paciente o seu estatuto de sujeito, ou seja, enquanto sujeito que tem de se escolher em situações concretas, com clareza de seu compromisso ontológico com os outros, com a sociedade. Dessa forma, tem como meta superar a alienação do sujeito.

Portanto, através de seus estudos biográficos, Sartre deixou muito claro todos os elementos essenciais para a realização de uma intervenção psicoterapêutica, apesar de ele mesmo não a ter realizado, por não ser um clínico e não ter ido para um consultório atender. Sua psicanálise existencial fornece uma teoria e uma metodologia fundamentais para se pensar a psicologia clínica em novos moldes. Só é preciso colocá-la em prática, como afirma o próprio Sartre.

Já foram realizadas algumas tentativas, ao nível mundial, de praticar a psicologia sartriana. A mais conhecida foi a realizada por Laing e Cooper, psiquiatras ingleses, que criaram comunidades terapêuticas na década de setenta (Cooper, 1982), utilizando-se do referencial sartriano. O próprio Sartre elaborou o prefácio do livro da dupla de pesquisadores, intitulado Razão e Violência (Laing \& Cooper, 1982), onde declara que o que mais o encantou no livro foi "a constante preocupação de realizar um approach 'existencial' dos doentes mentais". Afirma, também, sua convicção de que os esforços desses profissionais contribuirão para tornar a psiquiatria, finalmente, humana. No en- 
tanto, essa tentativa inglesa não foi fiel ao próprio pensamento sartriano, na medida em que se fundiu com outras metodologias e psicologias com ela incompatíveis (como a psicanálise kleiniana, por exemplo), utilizando-se do referencial sartriano como contribuições pontuais. Assim, apesar de assinalarem o potencial clínico da psicologia existencialista, elas não se constituíram na sistematização do conjunto de sua teoria e metodologia.

O aproveitamento do conjunto da obra sartriana na direção da consolidação de uma nova perspectiva para a psicologia e seus desdobramentos concretos para a realização de uma clínica vem sendo praticada, hodiernamente, por alguns profissionais de que temos notícias: há um grupo de psicólogos, filósofos e outros profissionais e pesquisadores em Florianópolis, Santa Catarina, reunidos em torno do $\mathrm{NUCA}^{6}$, que há mais de vinte anos vem se dedicando a estudar a obra de Sartre, e que está pondo em prática uma metodologia psicoterapêutica totalmente sustentada na filosofia e psicologia sartriana. Nos Estados Unidos, há uma psicóloga, Betty Cannon, que também realiza uma clínica sartriana nos moldes acima mencionados, conforme aparece em seu livro Sartre et la Psychanalyse (Cannon, 1993).

\section{VII - À guisa de uma conclusão}

Sartre participou ativamente do contexto da evolução do pensamento de seu tempo, tendo sérias preocupações com o papel das ciências na organização da sociedade onde estava inserido. Para que esse papel fosse efetivamente transformador, como julgava necessário, propunha que a filosofia, a antropologia e a psicologia fossem questionadas em seus fundamentos, já que elas fornecem o horizonte de inteligibilidade humana do sistema social vigente. Sua crítica mais contundente prendia-se ao fato de que esses conhecimentos transformam a realidade em uma mera abstração, em uma entidade metafísica, muito distante da realidade concreta dos indivíduos. Sob o horizonte dessas críticas, o francês partiu para refazer tais conhecimentos.

Seu projeto teórico inicial foi elaborar uma nova psicologia. A meio caminho, porém, compreendeu que só conseguiria propor uma nova perspectiva para essa ciência se revisse seus fundamentos ontológicos e antropológicos, pois os impasses da psicologia tinham ali sua âncora. Partiu para a elaboração de uma nova ontologia e, mais tarde, de uma nova antropologia. Mas, no fundo de suas obras, a temática da psicologia continuava presente e em constante elaboração. Seus empreendimentos biográficos foram exercícios práticos de sua psicologia em formulação.

Em sua trajetória teórica Sartre viabilizou: a) uma proposta metodológica concreta para a área em estudo - a psicanálise existencial - a partir de críticas epistemológicas à psicologia empírica e à psicanálise; b) um conjunto de reflexões no campo da psicopatologia, apontando para a superação da psicopatologia psiquiátrica ou psicanalítica e seus impasses de fundo biologicista e/ou subjetivista; c) um novo arcabouço teórico para a psicologia; d) exercícios de elaboração da "compreensão psicológica", etapa fundamental de qualquer processo psicoterapêutico, como podemos ver em suas biografias de Jean Genet e Flaubert. Todos esses empreendimentos demonstram que a obra de Sartre insere-se, também, no campo da psicologia clínica, com importantes contribuições para a superação dos impasses da área:

- no que tange à sua dimensão epistemológica, ao propor uma novo estatuto de cientificidade para a psicologia;

- no que tange à sua dimensão teórica, ao fornecer uma concepção ontológica, antropológica e psicológica que colocam o homem como ser histórico-social, compreendendo a personalidade e as complicações psicológicas como processos de construção do seu ser individual na relação com o contexto antropológico e sociológico, portanto, com sua faceta objetiva e subjetiva, tendo o homem como sujeito de seu ser;

- no que tange à dimensão metodológica, ao esboçar um novo método, "a psicanálise existencial", que viabiliza a investigação clínica e intervenção prática a partir das duas dimensões acima elencadas;

- a partir do equacionamento das questões epistemológicas, teóricas e metodológicas, adquirese condições de realizar a problematização das questões ideológicas e políticas dentro de um novo patamar, decorrentes de uma proposta efetiva de um novo fazer do psicólogo.

Dessa forma, Sartre construiu um novo arcabouço teórico-metodológico para a psicologia, que coloca a relação do homem com a sociedade em outras bases, fornecendo elementos teórico-epistemológicos para a necessária superação dos processos de alienação, solidão e enlouquecimento típicos da cultura contemporânea. 
Os conhecimentos psicológicos e filosóficos propostos por Sartre fornecem as condições necessárias para a viabilização de um momento pós-psiquiátrico, que supere os impasse gerados pela dialética entre a tese psiquiatrizante e sua antítese antipsiquiatrizante ou antimanicomial, conforme nos afirma Bertolino (Leone, 2000).

Consideramos como absolutamente necessária e enriquecedora uma reflexão sobre o pensamento sartriano para a realidade contemporânea, por constituirse em uma das mais inovadoras compreensões de homem e de sociedade contemporânea e, portanto, em uma reviravolta para as ciências hodiernas, principalmente em suas elaborações para a psicologia e, mais especificamente, para a psicologia clínica.

\section{REFERÊNCIAS}

Bertolino, P. (1979). Sartre: Ontologia e valores. Dissertação de Mestrado não publicada. Programa de Pós-Graduação em Filosofia, Pontifícia Universidade Católica do Rio Grande do Sul. Porto Alegre, RS.

Bertolino, P. (1995). Psicologia: Ciência e paradigma. Em Conselho Federal de Psicologia (Org.), Psicologia no Brasil: Direções epistemológicas (pp. 13-40). Brasília: Conselho Federal de Psicologia.

Bertolino, P. (2004). Modelos científicos. Obtido em 10 de março de 2004 do World Wide Web: http://www.nuca.org.br.

Beauvoir, S. (1960). La force de l'âge (I e II). Paris: Gallimard. Col. Folio.

Campos, F. C. B. (1992). Psicologia e saúde: Repensando práticas. São Paulo: Hucitec.

Cannon, B. (1993). Sartre et la psychanalyse. Paris: PUF.

Cohen-Solal, A. (1986). Sartre. São Paulo: L\&PM Editores.

Conselho Federal de Psicologia (1988). Quem é o psicólogo brasileiro? São Paulo: EDICON.

Conselho Federal de Psicologia (1992). Psicólogo brasileiro: Construção de novos espaços. Campinas: Tomo.

Conselho Federal de Psicologia (1994). Psicólogo brasileiro: Práticas emergentes e desafios profissionais. São Paulo: Casa do Psicólogo.

Contat, M. \& Rybalka, M. (1970). Les écrits de Sartre. Paris: Gallimard.

Cooper, D. (1982). Psiquiatria e antipsiquiatria. São Paulo: Perspectivas.

Correbyter, V. (2000). Sartre face à la phénoménologie. Bruxelles: Ousia.

Jaspers, K. (1979) Psicopatologia geral: Psicologia compreensi$v a$, explicativa e fenomenologia. ( $2^{\mathrm{a}}$ ed.) Rio de Janeiro: Atheneu.

Laing, R. \& Cooper, D (1982). Razão e violência: Uma década da filosofia de Sartre (1950-1960). (2ª ed.) Petrópolis: Vozes.

Leone, E. (2000). Balanço da produção acadêmica brasileira no campo da saúde mental - 1990/97. Revista de Ciências
Humanas. Série Especial Temática - Saúde Mental: Uma perspectiva crítica.

Marx, K. \& Engels, F. (1987). A ideologia alemã (I- Feuerbach). ( $7^{\mathrm{a}}$ ed.) São Paulo: Hucitec.

Mensh, I. (1971). Psicologia clinica: Ciencia y profesion. Buenos Aires: Paidos.

Moutinho, L. (1995). Sartre: Psicologia e fenomenologia. São Paulo: Brasiliense.

Politzer, G. (1965). Psicologia concreta. Buenos Aires: Jorge Alvarez Ed.

Politzer, G. (1998). Crítica dos fundamentos da psicologia: A psicologia e a psicanálise. Piracicaba: UNIMEP.

Sartre, J-P. (1936). L'imagination. Paris: PUF.

Sartre, J-P. (1937). La transcendance de l'ego: Esquisse d'une description phénoménologique. Paris: J. Vrin.

Sartre, J-P. (1938). La nausée. Paris: Gallimard.

Sartre, J-P. (1939). Esquisse d'une théorie des émotions. Paris: Hermann.

Sartre, J-P. (1940). L'imaginaire: Psychologie phénoménologique de l'imagination. Paris: Gallimard.

Sartre, J-P. (1943). L'être et le néant: Essai d'ontologie phénoménologique. Paris: Gallimard.

Sartre, J-P. (1947). Baudelaire. Paris: Gallimard. Col. Folio.

Sartre, J-P. (1952). Saint Genet: Comédien et martyr. Paris: Gallimard.

Sartre, J-P. (1960). Critique de la raison dialectique (précédé de Question de Méthode). Paris: Gallimard.

Sartre, J-P. (1968). Situações I. Lisboa: Publicações EuropaAmérica.

Sartre, J-P. (1971). L'idiot de la famille: Gustave Flaubert, de 1821 a 1857. Paris: Gallimard.

Sartre, J-P. (1975). Esboço de uma teoria das emoções. Lisboa: Presença.

Sartre, J-P. (1986). Freud, além da alma. Rio de Janeiro: Nova Fronteira.

Sartre, J-P. (1987). A imaginação. (3 ${ }^{\mathrm{a}}$ ed.) São Paulo: Nova Cultural. Col. Os Pensadores.

Sartre, J-P. (1994). A transcendência do ego. Lisboa: Colibri.

Sartre, J.-P. (1996). O imaginário: Psicologia fenomenológica da imaginação. São Paulo: Ática.

Sartre, J-P. (1997). O ser e o nada: Ensaio de ontologia fenomenológica. $2^{\mathrm{a}}$ ed. Petrópolis: Vozes.

Sartre, J-P. (2000). A náusea. Rio de Janeiro: Nova Fronteira.

Sartre, J-P. (2002). Saint Genet: Ator e mártir. Petrópolis: Vozes.

Sartre, J-P. (2002a). Crítica da razão dialética - Precedido de Questão de Método. Rio de Janeiro: DP\&A.

Schneider, D. (2002). Novas perspectivas para a psicologia clínica: Um estudo a partir da obra Saint Genet: comédiet et martyr de Jean-Paul Sartre. Tese de doutorado não publicada. Programa de Pós-Graduação em Psicologia Clínica da Pontifícia Universidade Católica de São Paulo. São Paulo, SP.

Vygotski, L. S. (1996). Teoria e método em psicologia. São Paulo: Martins Fontes. 


\section{Notas:}

${ }^{1}$ Artigo extraído da tese de doutorado da autora: "Novas Perspectivas para a Psicologia Clínica: Um estudo a partir da obra Saint Genet: Comédien et martyr de Jean-Paul Sartre. Programa de Pós-Graduação em Psicologia Clínica da PUC/SP, 2002.

${ }^{2}$ As referências às obras de Sartre virão seguidas de duas datas. A primeira é a de sua publicação no original francês; a segunda é de sua tradução para o português, mais especificamente a da edição que a autora dispõe. Nas referências bibliográficas, com a finalidade de subsidiar os leitores interessados na obra sartriana, serão referenciados de forma independente o livro no seu original francês e sua tradução para o português.

${ }^{3}$ Livro ainda sem edição para o português.

${ }^{4}$ Neste artigo, infelizmente, não temos condições, em termos do seu objetivo e do espaço disponível, de descrever a filosofia e psicologia sartrianas em seus detalhes, apesar de sua importância para melhor compreensão do tema proposto. Dessa forma, realizamos aqui sua síntese e indicamos a tese da autora (Schneider, 2002) para os interessados em conhecer mais profundamente esses outros aspectos.

${ }^{5}$ Em seus livros escritos nos anos 1930, principalmente no Esboço de uma Teoria das Emoções, O Imaginário e O Ser e o Nada (ops. cits.), Sartre tece uma série de críticas à psicologia empírica (que abarcaria a psicologia estruturalista do final do século XIX e início do século XX, assim como sua herdeira, a psicologia behaviorista), bem como à psicanálise, que ele também chama de empírica. Essas críticas vão desde aspectos propriamente epistemológicos, onde discute a problemática do empirismo, que faz com que a psicologia "enquanto se pretenda como ciência, não faça mais do que uma junção de fatos heterogêneos, dos quais a maior parte não tem ligação entre si” (Sartre, 1939, p. 12), passando por aspectos propriamente teóricos, como o questionamento filosófico aos pressupostos da metapsicologia psicanalítica, com seus conceitos de inconsciente, censura, pulsão etc. Diz Sartre (1943, p. 98) "sem dúvida, se rejeitamos a linguagem e a mitologia coisificante da psicanálise, veremos que a censura, para agir com discernimento, deve saber o que reprime. (...) Seria possível conceber um saber ignorante de si?”. Essas entre outras críticas, levam-no, inclusive a questionar a metodologia interpretativa da psicanálise, quando discute que a simbólica universal utilizada pelos psicanalistas realiza generalizações que desconsideram a idiossincrasia de cada caso clínico, por estar sustentada em uma noção determinista (Sartre, 1943). Essas entre outras críticas demonstram o corte epistemológico e teórico pretendido por Sartre em relação ao que ele designa de psicologia e psicanálise empíricas. Verificar esses argumentos na tese da autora (Schneider, 2002).

${ }^{6}$ Núcleo Castor - estudos e atividades em existencialismo - site: www.nuca.org.br. Neste site há relatos de vários casos clínicos trabalhos na perspectiva da psicologia clínica sartriana, que ajudam a elucidar em termos práticos a discussão teórica aqui realizada.

\section{Sobre a autora:}

Daniela Ribeiro Schneider: Professora do Departamento de Psicologia da UFSC, Psicóloga, Doutora em Psicologia Clínica, Mestre em Educação, Especialista em Psicologia Clínica, com Formação em Psicologia Existencialista pelo NUCA (Núcleo Castor - Estudos e Atividades em Existencialismo - www.nuca.org.br).

Endereço para correspondência: Rua Padre Lourenço R. de Andrade, 650 - Santo Antônio de Lisboa - 88050-400 - Florianópolis/SC Endereço eletrônico: danis@cfh.ufsc.br. 